\title{
Estimating the economic value of absorbing and storing carbon in dipterocarp forests in Ia Pa district, Gia Lai province
}

\section{Trang T. Q. Nguyen*, \& Phuong T. B. Tran}

Faculty of Environment, Ho Chi Minh University of Natural Resources and Environment, Ho Chi Minh City, Vietnam

ARTICLE INFO
Research Paper
Received: April 10, 2019
Revised: May 18, 2019
Accepted: July 25, 2019
Keywords
Absorption $\mathrm{CO}_{2}$
Cumulative $\mathrm{CO}_{2}$
Dry dipterocarp forest
Greenhouse gas
IaPa district
*Corresponding author
Nguyen Thi Quynh Trang
Email: ntqtrang@hcmunre.edu.vn

Cited as: Nguyen, T. T. Q., \& Tran, P. T. B. (2019). Estimating the economic value of absorbing and storing carbon in dipterocarp forests in Ia Pa district, Gia Lai province. The Journal of Agriculture and Development 18(5), 79-86.

\section{ABSTRACT}

Dry dipterocarp forest is one of the ecosystems that features variety of rare plants and animals. The forest in Ia Pa district, Gia Lai province is declining owing to illegal logging and encroachment of forest land for cultivation. Forest degradation can reduce $\mathrm{CO}_{2}$ sequestration, contributing to increasing greenhouse gas emission and global warming. The study was carried out in the 4 quadrats (each $2,500 \mathrm{~m}^{2}=50 \times 50 \mathrm{~m}$ ) in dry dipterocarp forest of Ia Pa district. In each quadrat, 5 sub-quadrats (each $25 \mathrm{~m}^{2}=5 \times 5 \mathrm{~m}$ ) were set up, one at a central point and four at four corners of the quadrat, respectively. Based on the relationship between carbon stock and above-ground biomass, we found that $\mathrm{CO}_{2}$ accumulation in dry dipterocarp forest was 105.6 tons/ha corresponding to the economic value of $12,299,760 \mathrm{VND} / \mathrm{ha}$. Thus, it is necessary to improve forest quality towards sustainable management of dry dipterocarp forest ecosystem and increase the economic value of the forest with respect to environmental services. 


\title{
Ước tính giá trị kinh tế từ việc hấp thụ và lưu trữ cacbon của rừng khộp tại huyện Ia Pa, tỉnh Gia Lai
}

\author{
Nguyễn Thị Quỳnh Trang* \& Trần Thị Bích Phượng \\ Khoa Môi Trường, Trường Đại Học Tài Nguyên và Môi Trường TP.HCM, TP. Hồ Chí Minh
}

\section{THÔNG TIN BÀI BÁO}

Bài báo khoa học

Ngày nhận: 10/04/2019

Ngày chỉnh sửa: 18/05/2019

Ngày chấp nhận: 25/07/2019

Từ khóa

Hấp thụ $\mathrm{CO}_{2}$

Huyện $\mathrm{IaPa}$

Khí nhà kính

Lưu trữ $\mathrm{CO}_{2}$

Rừng khộp

*Tác giả liên hệ

Nguyễn Thị Quỳnh Trang

Email: ntqtrang@hcmunre.edu.vn

\section{TÓM TẮT}

Rừng khộp là một trong những rừng có hệ sinh thái đặc trưng với nhiều loại động vật quí hiếm. Diện tích rừng khộp thuộc huyện Ia $\mathrm{Pa}$, tỉnh Gia Lai đang suy giảm do người dân khai thác rừng trái phép, lấn chiếm đất rừng làm nương rẫy. Suy giảm rừng làm giảm khả năng hấp thụ $\mathrm{CO}_{2}$ góp phần làm gia tăng phát thải khí nhà kính vào môi trường, gây nên hiện tượng nóng lên toàn cầu. Nghiên cứu được thực hiện trong 4 ô tiêu chuẩn sơ cấp $\left(2.500 \mathrm{~m}^{2}=50 \times 50 \mathrm{~m}\right)$ tại rừng khộp, huyện Ia $\mathrm{Pa}$ với 5 ô thứ cấp $\left(25 \mathrm{~m}^{2}=5 \times 5 \mathrm{~m}\right)$ được bố trí ở 4 góc và 1 ô ở trung tâm của mỗi ô tiêu chuẩn sơ cấp. Dựa vào mối tương quan giữa cacbon và các loài thực vật trên mặt đất, nghiên cứu đã tính được lượng CO2 tích lũy của rừng khộp là 105,6 tấn/ha, tương ứng với giá trị kinh tế trên thị trường là 12.299.760 VNĐ/ha. Như vậy, cần thiết nâng cao chất lượng rừng hướng tới quản lý bền vững hệ sinh thái rừng khộp, tạo cơ sở nâng cao giá trị kinh tế của rừng khộp dựa vào giá trị môi trường.

\section{1. Đặt Vấn Đề}

Mối quan hệ giữa biến đổi khí hậu (BĐKH) và hàm lượng phát thải khí $\mathrm{CO}_{2}$ là một vấn đề đang được quan tâm trên toàn cầu. Theo Hội đồng liên chính phủ về $\mathrm{BĐKH} \mathrm{dự} \mathrm{báo} \mathrm{khoảng} 1,5$ tỷ tấn cacbon sẽ phát thải hàng năm, chiếm $1 / 5$ khí $\mathrm{CO}_{2}$ phát thải trên toàn thế giới do thay đổi sử dụng đất rừng (IPCC, 2006). Nhằm hỗ trợ chương trình giảm phát thải khí nhà kính do mất rừng và suy thoái rừng ở các nước đang phát triển, quản lý bền vững tài nguyên rừng nâng cao trữ lượng lưu trữ cacbon thì việc nghiên cứu trữ lượng lưu trữ cacbon để đóng góp vào việc ứng phó $\mathrm{BĐKH}$ là cần thiết.

Ở Việt Nam, rừng khộp phân bố ở một số tỉnh thuộc khu vực Tây Nguyên như Gia Lai, Kon Tum, Đắk Lắk, Lâm Đồng,... Rừng khộp ngoài vai trò cung cấp lâm sản như gỗ còn có vai trò điều hòa khí hậu, bảo vệ môi trường sinh thái, hấp thụ được lượng lớn khí $\mathrm{CO}_{2}$ làm giảm khả năng phát thải khí vào môi trường,... Tuy nhiên, hiện nay những giá trị môi trường của rừng vẫn chưa được lượng hóa cụ thể, dẫn đến việc người dân chưa thấy được vai trò quan trọng của rừng tại khu vực. Xuất phát từ thực tế trên, nghiên cứu này được thực hiện nhằm mục đích đánh giá khả năng hấp thụ, lưu trữ cacbon của rừng khộp thuộc huyện IaPa, tỉnh Gia Lai. Trên cơ sở đó tính toán được giá trị kinh tế từ giá trị môi trường của rừng khộp mang lại.

\section{Vật Liệu và Phương Pháp Nghiên Cứu}

\subsection{Khu vực nghiên cứu}

Ia Pa là một huyện phía Đông Nam của tỉnh Gia Lai. Phía Bắc giáp các huyện Chư Sê, Mang Yang, Kông Chro; phía Nam giáp huyện Krông Pa; Đông giáp huyện Đồng Xuân, tỉnh Phú Yên và Tây giáp huyện Phú Thiện, thị xã Ayun Pa. Huyện Ia $\mathrm{Pa}$ tập trung chủ yếu là rừng khộp. 
Đây là hệ sinh thái đặc trưng với các cây thuộc họ Dầu lá rộng (Dipterocarpaceae) chiếm ưu thế. Tổng diện tích đất lâm nghiệp huyện Ia $\mathrm{Pa}$ là 53.391,75 ha. Trong đó, diện tích rừng khộp tự nhiên là 46.869,37 ha, rừng trồng 47,17 ha, đất lâm nghiệp chưa có rừng $6.475,21$ ha (IPDFPD, 2018).

\subsection{Phương pháp nghiên cứu}

\subsubsection{Phương pháp điều tra thực địa}

Đề tài tiến hành lập 4 ô tiêu chuẩn (OTC) để tính toán giá trị trung bình cho khu vực nghiên cứu (Bảng 1). Mỗi OTC (còn gọi là ô sơ cấp) có diện tích $2.500 \mathrm{~m}^{2}(50 \times 50 \mathrm{~m})$ để điều tra tầng cây cao. Trong mỗi OTC sẽ bố trí 5 ô thứ cấp bao gồm 4 ô ở 4 góc và 1 ô ở trung tâm của ô sơ cấp để điều tra tầng cây bụi thảm tươi và vật rơi rụng (VRR), mỗi ô diện tích là $25 \mathrm{~m}^{2}(5 \times 5$ m) (Vu \& Vo, 2014). Trong mỗi OTC sẽ lấy điểm trung tâm với tọa độ như sau:

Đối với tầng cây cao: Xác định tên cây, đo đường kính cây $\left(\mathrm{D}_{1,3}\right)$ và chiều cao cây $(\mathrm{Hvn})$ của toàn bộ cây gỗ có đường kính $\mathrm{D}_{1,3}>30 \mathrm{~cm}$ trong ô sơ cấp; đo $\mathrm{H}_{\mathrm{vn}}$ của toàn bộ cây gỗ có $\mathrm{D}_{1,3}=5$ $30 \mathrm{~cm}$ trong ô thứ cấp để xác định tầng cây cao. Chúng tôi xác định lượng cacbon lưu trữ trong cây dựa vào việc đo đếm sinh khối tầng cây gỗ (Vu \& Vo, 2014).

Đối với tầng cây bụi, thảm tươi: Sử dụng phương pháp chặt hạ để đo đếm sinh khối của tầng cây bụi, thảm tươi. Tiến hành tách riêng từng bộ phận thân, lá, cành và cân ngay tại hiện trường để xác định sinh khối tươi. Thu $0,5 \mathrm{~kg}$ mỗi bộ phận thân cành, lá của cây bụi, thảm tươi đem về phòng thí nghiệm sấy để xác định sinh khối khô.

Tiến hành thu nhặt toàn bộ VRR trong ô có diện tích $25 \mathrm{~m}^{2}$, cân ngay tại hiện trường để xác định sinh khối tươi. Thu $0,5 \mathrm{~kg}$ VRR đem về phòng thí nghiệm sấy khô để xác định sinh khối khô. Số liệu trọng lượng được sử dụng để phân tích sinh khối của thực vật khu vực nghiên cứu.

\subsubsection{Phương pháp phân tích, tính toán, xử lý số liệu}

Đối với tầng cây cao: Mối quan hệ giữa lượng cacbon lưu trữ trên mặt đất của cây cá thể của loài ưu thế trong sinh cảnh rừng khộp với $\mathrm{D}_{1,3}$ và Hvn để tính lượng cacbon tích lũy trong tầng cây gỗ được thể hiện trong Bảng 2.
Đối với cây bụi thảm tươi và VRR: Xác định sinh khối khô.

Độ ẩm của từng mẫu lá, thân cành của thảm tươi và VRR sẽ được tính theo công thức:

$$
\mathrm{D}(\%)=\left[\left(\mathrm{m}_{1}-\mathrm{m}_{2}\right) / \mathrm{m}_{1}\right] \times 100
$$

Trong đó, $\mathrm{D}$ là độ ẩm (\%); $\mathrm{m}_{1}$ là trọng lượng tươi của mẫu; $m_{2}$ là trọng lượng khô của mẫu.

Sinh khối khô của từng bộ phận thành phần của thảm tươi tính bằng $\mathrm{kg}$ bao gồm thân cây, lá cây bụi, cành cây bụi và vật rơi rụng được tính theo các công thức:

$$
\begin{aligned}
& \mathrm{SKK}(\mathrm{tc})=\operatorname{SKT}(\mathrm{tc}) \times(1-\mathrm{D}(\mathrm{tc})) \\
& \operatorname{SKK}(\mathrm{lá})=\operatorname{SKT}(\mathrm{lá}) \times(1-\mathrm{D}(\mathrm{lá})) \\
& \mathrm{SKK}(\mathrm{c})=\operatorname{SKT}(\mathrm{c}) \times(1-\mathrm{D}(\mathrm{c})) \\
& \mathrm{SKK}(\mathrm{vrr})=(\operatorname{SKT}(\mathrm{vrr}) \times(1-\mathrm{D}(\mathrm{vrr}))
\end{aligned}
$$

Trong đó, SKK(tc), SKK(lá), SKK(c), SKT(vrr) là sinh khối khô tính bằng $\mathrm{kg}$ của thân cây, lá, cành, vật rơi rụng; SKT(tc), SKT(lá), SKT(c), SKT(vrr) lần lượt là sinh khối tươi tính bằng $\mathrm{kg}$ của thân cây, lá, cành, vật rơi rụng; $\mathrm{D}(\mathrm{tc}), \mathrm{D}(\mathrm{lá}), \mathrm{D}(\mathrm{vrr}), \mathrm{D}(\mathrm{c}), \mathrm{D}(\mathrm{vrr})$ lần lượt là độ ẩm tính bằng $\%$ của thân cây, lá, cành và vật rợi rụng.

Tổng sinh khối khô thảm tươi, cây bụi được tính như sau:

$$
\begin{aligned}
& \operatorname{SKK}_{\text {cây bụi thảm tươi }}=\operatorname{SKK}(\mathrm{tc})+\mathrm{SKK}(\text { lá })+ \\
& \operatorname{SKK}(\mathrm{c})
\end{aligned}
$$

Lượng cacbon tích lũy phần trên mặt đất trong các trạng thái lớp phủ thực vật bao gồm cacbon tích lũy trong thảm thực vật (cây gỗ, cây bụi, thảm tươi) và vật rơi rụng. Lượng cacbon tích lũy được tính dựa trên tổng SKK trên mặt đất theo công thức sau:

$$
\mathrm{W}_{\text {cacbon }}=\mathrm{CF} \times \mathrm{DW}_{\text {above }}(\text { tấn } \mathrm{C} / \mathrm{ha})
$$

Trong đó, $\mathrm{CF}$ là hệ số hàm lượng cacbon; $\mathrm{CF}$ đối với tầng cây gỗ, tầng cây bụi và thảm tươi là 0,47 ; CF đối với tầng vật rụng là 0,37 (IPCC, 2006).

$\mathrm{W}_{\text {cacbon là lượng cacbon tích lũy trong sinh }}$ khối (tấn/ha); DW above là lượng sinh khối khô trên mặt dất (tấn/ha). $\mathrm{DW}_{\text {above1 }}=\mathrm{W}_{\text {wood }}+$ $\mathrm{W}_{\text {shrub }}\left(\right.$ tấn $/$ ha); $\mathrm{DW}_{\text {above2 }}=\mathrm{W}_{\text {litter }}($ tấn $/$ ha $)$.

$\mathrm{W}_{\text {wood là lượng sinh khối khô của tầng cây gỗ }}$

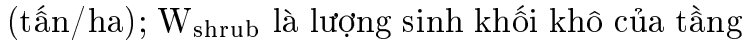
cây bụi, thảm tươi (tấn/ha); $\mathrm{W}_{\text {litter là lượng sinh }}$ khối khô của tầng vật rụng (tấn/ha). 
Bảng 1. Tọa độ trung tâm của $4 \mathrm{OTC}^{1}$

\begin{tabular}{cccc}
\hline \multirow{2}{*}{ OTC $^{1}$} & \multirow{2}{*}{ Vị trí } & \multicolumn{2}{c}{ Tọa độ } \\
\cline { 3 - 4 } & & OX & OY \\
\hline 1 & Lô 3, khoảnh 3, tiểu khu 1251 & 503.130 & 1484.124 \\
2 & Lô 1, khoảnh 3, tiểu khu 1248 & 504.965 & 1484.196 \\
3 & Lô 7, khoảnh 5, tiểu khu 1248 & 506.268 & 1483.728 \\
4 & Lô 4, khoảnh 8, tiểu khu 1244 & 507.939 & 1486.081 \\
\hline
\end{tabular}

${ }^{1} \mathrm{OTC}$ : Ô tiêu chuẩn.

Bảng 2. Phương trình tương quan giữa lượng cacbon trên mặt đất của cây cá thể loài ưu thế trong sinh cảnh rừng khộp với $\mathrm{D}_{1,3}$ và $\mathrm{H}_{\mathrm{vn}}$

\begin{tabular}{ll}
\hline Loài & Phương trình quan hệ̣ \\
\hline Cà chít & $\mathrm{C}_{\mathrm{ct}}=0,710 \times\left(\sqrt{\mathrm{D}_{1,3}^{2} \times \mathrm{H}_{\mathrm{vn}}}\right)^{1,170}$ \\
Cẩm liên & $\mathrm{C}_{\mathrm{ct}}=0,051 \times\left(\sqrt{\mathrm{D}_{1,3}^{2} \times \mathrm{H}_{\mathrm{vn}}}\right)^{1,695}$ \\
Chiêu liêu đen & $\mathrm{C}_{\mathrm{ct}}=0,068 \times\left(\sqrt{\mathrm{D}_{1,3}^{2} \times \mathrm{H}_{\mathrm{vn}}}\right)^{1,681}$ \\
Chiêu liêu ổi & $\mathrm{C}_{\mathrm{ct}}=0,229 \times\left(\sqrt{\mathrm{D}_{1,3}^{2} \times \mathrm{H}_{\mathrm{vn}}}\right)^{1,400}$ \\
Dầu đồng & $\mathrm{C}_{\mathrm{ct}}=0,025 \times\left(\sqrt{\mathrm{D}_{1,3}^{2} \times \mathrm{H}_{\mathrm{vn}}}\right)^{1,891}$ \\
Dẩu trà beng & $\mathrm{C}_{\mathrm{ct}}=0,024 \times\left(\sqrt{\mathrm{D}_{1,3}^{2} \times \mathrm{H}_{\mathrm{vn}}}\right)^{1,996}$ \\
Chung các loài cây & $\mathrm{C}_{\mathrm{ct}}=0,055 \times\left(\sqrt{\mathrm{D}_{1,3}^{2} \times \mathrm{H}_{\mathrm{vn}}}\right)^{1,669}$ \\
\hline
\end{tabular}

2.2.3. Phương pháp đánh giá giá trị tài nguyên và môi trường

Nghiên cứu sử dụng các phương pháp lượng giá hiện hành để lượng giá giá trị cacbon của rừng tại rừng khộp huyện Ia $\mathrm{Pa}$.

Công thức tổng quát để xác định là: $\mathrm{V}_{\mathrm{CO}_{2}}=$ $\mathrm{M}_{\mathrm{CO}_{2}}$ x Pc (Luong \& ctv., 2011).

Lượng $\mathrm{CO}_{2}$ hấp thụ chuyển đổi từ cacbon tích lũy: $\mathrm{M}_{\mathrm{CO}_{2}}($ tấn/ha $)=\mathrm{W}_{\text {Cacbon }} \times(44 / 12)$.

Trong đó, $\mathrm{V}_{\mathrm{CO}_{2}}$ là giá trị kinh tế trên cơ sở hấp thụ $\mathrm{CO}_{2}$ bằng USD hoặc đồng cho 1 ha; $\mathrm{M}_{\mathrm{CO}_{2}}$ là lượng $\mathrm{CO}_{2}$ tính bằng tấn $\mathrm{CO}_{2} /$ ha; $\mathrm{Pc}$ là giá bán tín chỉ cacbon CER trên thị trường tính bằng USD hoặc đồng/tấn $\mathrm{CO}_{2}$.

\section{Kết Quả và Thảo Luận}

\subsection{Lượng cacbon lưu trữ trong tầng cây gỗ}

Kết quả điều tra tại khu vực nghiên cứu trong 4 OTC sơ cấp được tính toán bình quân trong 1 ha rừng khộp xác định có 22 loài cây của tầng cây cao gồm: Bằng lăng (Lagerstromia flos- reginae Retz), Bình linh (Vitex pubescens Vahl), Bứa núi (Garcinia oliveri Pierre), Cà chít (Shorea obtusa Wall), Cám (Parinarium anamensis Han $c e)$, Cẩm liên (Pentaome siamensis Kniz), Căm xe (Xylia dolabriformis Benth), Chiêu liêu (Terminalia Chebula Roxb), Dầu lông (Dipterocarpus sp), Gạo (Bombax malabaricum D.C), Gáo vàng (Indina sessifolia Hook), Ké (Nephelium $\mathrm{sp}$ ), Kơ nia (Irvingia malayana Oliver), Thành ngạnh (Cratoxylon formosum B.et.H), Thầu tấu (Aporosa microcalvx Hassh), Trám hồng ( $\mathrm{Ca}$ narium sp), Trân sừng (Eugenia chanlos Gag$n e p$ ), Vừng (Careya sphaerica Roxb), xoài rừng (Mangiera indica Linn). Từ số lượng các loài cây và Bảng 2 , lượng lưu trữ cacbon trong các cá thể được tính toán và thể hiện trong Bảng 3 .

Từ Bảng 3 cho thấy rằng, ở tầng cây gỗ lượng cacbon lưu trữ là cao nhất là loài Cà chít (đạt 7,13 tấn/ha chiếm $25,26 \%$ ), tiếp đến là Dầu lông (đạt 4,6 tấn/ha chiếm 16,29\%) và Chiêu liêu (đạt 2,7 tấn/ha chiếm $9,56 \%$ ) còn lại là các loài cây khác. Như vậy, rừng khộp ở Ia Pa đặc trưng với 3 nhóm cây chính là Cà chít, Dầu lông, và Chiêu liêu với mật độ và phân bố cây chiếm đa số. 
Bảng 3. $\mathrm{D}_{1,3}, \mathrm{H}_{\mathrm{vn}}$ và lượng cacbon lưu trữ của các loài cây gỗ trong $4 \mathrm{OTC}$ sơ cấp

\begin{tabular}{|c|c|c|c|c|c|c|c|}
\hline $\mathrm{OTC}^{1}$ & STT & Loài & $\begin{array}{c}\text { Số lượng } \\
\text { cây }\end{array}$ & $\begin{array}{l}D_{1,3} \\
(\mathrm{~cm})\end{array}$ & $\begin{array}{l}\mathrm{H}_{\mathrm{vn}} \\
(\mathrm{m})\end{array}$ & $\begin{array}{c}\text { Cct } \\
(\mathrm{kg} / \text { cây })\end{array}$ & $\begin{array}{c}\text { Cct } \\
(\mathrm{kg} / \text { cây })\end{array}$ \\
\hline \multirow{13}{*}{1} & 1 & Bình linh & 4 & 14,3 & 13,5 & 40,91 & 0,65 \\
\hline & 2 & Cà chít & 17 & 13,8 & 13,7 & 70,78 & 4,81 \\
\hline & 3 & Cám & 1 & 14 & 12 & 35,80 & 0,14 \\
\hline & 4 & Cẩm liên & 1 & 13 & 12 & 32,38 & 0,13 \\
\hline & 5 & Căm xe & 3 & 15 & 13 & 42,94 & 0,52 \\
\hline & 6 & Chiêu liêu & 5 & 17,2 & 15,8 & 82,59 & 1,65 \\
\hline & 7 & Dầu lông & 17 & 16,5 & 14,3 & 54,51 & 3,71 \\
\hline & 8 & Kơ nia & 3 & 15,3 & 14 & 47,21 & 0,57 \\
\hline & 9 & Sp6 & 2 & 19 & 17,5 & 81,64 & 0,65 \\
\hline & 10 & Sp7 & 2 & 21,5 & 16 & 93,12 & 0,74 \\
\hline & 11 & Thành ngạnh & 2 & 13,5 & 15 & 40,58 & 0,32 \\
\hline & 12 & Thầu tấu & 2 & 15 & 13,5 & 44,31 & 0,35 \\
\hline & 13 & Trâm & 3 & 17,7 & 14,7 & 62,71 & 0,75 \\
\hline \multicolumn{6}{|c|}{ Tổng cộng: } & 729,49 & 15,01 \\
\hline \multirow{13}{*}{2} & 1 & Bằng lăng & 2 & 21 & 22,5 & 119,00 & 0,95 \\
\hline & 2 & Bình linh & 4 & 16,5 & 18,8 & 68,49 & 1,10 \\
\hline & 3 & Cà chít & 19 & 15,3 & 21,5 & 103,95 & 7,90 \\
\hline & 4 & Cám & 4 & 24 & 22,5 & 148,71 & 2,38 \\
\hline & 5 & Căm xe & 4 & 15 & 21,8 & 66,10 & 1,06 \\
\hline & 6 & Chiêu liêu & 9 & 18,6 & 22,7 & 127,73 & 4,60 \\
\hline & 7 & Dầu lông & 17 & 16,2 & 21,9 & 75,45 & 5,13 \\
\hline & 8 & Gáo vàng & 1 & 12 & 24 & 49,35 & 0,20 \\
\hline & 9 & Kơ nia & 4 & 30,3 & 26,5 & 251,53 & 4,02 \\
\hline & 10 & Sp7 & 3 & 14,3 & 23,3 & 64,52 & 0,77 \\
\hline & 11 & Thành ngạnh & 2 & 18 & 23 & 93,71 & 0,75 \\
\hline & 12 & Thầu tấu & 2 & 11,5 & 25 & 47,56 & 0,38 \\
\hline & 13 & Trâm & 4 & 19,5 & 25 & 114,82 & 1,84 \\
\hline \multicolumn{5}{|c|}{ Tổng cộng: } & & 1330,91 & 31,08 \\
\hline \multirow{18}{*}{3} & 1 & Bằng lăng & 1 & 23 & 32 & 185,84 & 0,74 \\
\hline & 2 & Bình linh & 8 & 20 & 20,6 & 101,91 & 3,26 \\
\hline & 3 & Bứa núi & 1 & 20 & 22 & 107,65 & 0,43 \\
\hline & 4 & Cà chít & 16 & 20,2 & 21,6 & 144,27 & 9,23 \\
\hline & 5 & Cám & 3 & 22,7 & 20,3 & 124,36 & 1,49 \\
\hline & 6 & Căm xe & 3 & 17,3 & 19,7 & 77,07 & 0,92 \\
\hline & 7 & Chiêu liêu & 6 & 16,7 & 21,5 & 101,81 & 2,44 \\
\hline & 8 & Dầu lông & 15 & 18,9 & 20,8 & 93,48 & 5,61 \\
\hline & 9 & Gạo & 1 & 14 & 16 & 45,51 & 0,18 \\
\hline & 10 & Gáo vàng & 1 & 12 & 17 & 37,01 & 0,15 \\
\hline & 11 & Kơ nia & 3 & 30,3 & 25 & 239,59 & 2,88 \\
\hline & 12 & $\mathrm{Sp} 7$ & 3 & 13 & 19,7 & 47,84 & 0,57 \\
\hline & 13 & Thẩu tấu & 1 & 15 & 17 & 53,71 & 0,21 \\
\hline & 14 & Trám & 1 & 18 & 19 & 79,90 & 0,32 \\
\hline & 15 & Trâm & 1 & 12 & 16 & 35,18 & 0,14 \\
\hline & 16 & Vừng quả to & 1 & 14 & 17 & 47,87 & 0,19 \\
\hline & 17 & Xoài rừng & 1 & 40 & 21 & 329,30 & 1,32 \\
\hline & \multicolumn{5}{|c|}{ Tổng cộng: } & 1852,30 & 30,10 \\
\hline
\end{tabular}


Bảng 3. $\mathrm{D}_{1,3}, \mathrm{H}_{\mathrm{vn}}$ và lượng cacbon lưu trữ của các loài cây gỗ trong 4 OTC sơ cấp (tiếp theo trang 83)

\begin{tabular}{|c|c|c|c|c|c|c|c|}
\hline $\mathrm{OTC}^{1}$ & STT & Loài & $\begin{array}{c}\text { Số lượng } \\
\text { cây }\end{array}$ & $\begin{array}{l}D_{1,3} \\
(\mathrm{~cm})\end{array}$ & $\begin{array}{l}\mathrm{H}_{\mathrm{vn}} \\
(\mathrm{m})\end{array}$ & $\begin{array}{c}\text { Cct } \\
(\mathrm{kg} / \text { cây })\end{array}$ & $\begin{array}{c}\text { Cct } \\
(\mathrm{kg} / \text { cây })\end{array}$ \\
\hline \multirow{17}{*}{4} & 1 & Bằng lăng & 6 & 20,7 & 20,7 & 108,37 & 2,60 \\
\hline & 2 & Bình linh & 3 & 22,7 & 23 & 138,02 & 1,66 \\
\hline & 3 & Bứa núi & 1 & 20 & 24 & 115,76 & 0,46 \\
\hline & 4 & Cà chít & 11 & 20,2 & 23 & 149,67 & 6,59 \\
\hline & 5 & Cám & 1 & 12 & 19 & 40,61 & 0,16 \\
\hline & 6 & Căm xe & 2 & 14 & 19 & 52,53 & 0,42 \\
\hline & 7 & Chiêu liêu & 7 & 14,1 & 20,7 & 74,20 & 2,08 \\
\hline & 8 & Dầu lông & 11 & 17,7 & 22,2 & 88,46 & 3,89 \\
\hline & 9 & Gáo vàng & 4 & 19,3 & 24,3 & 110,22 & 1,76 \\
\hline & 10 & Ké & 1 & 30 & 30 & 274,37 & 1,10 \\
\hline & 11 & Kơ nia & 3 & 35 & 24,7 & 301,73 & 3,62 \\
\hline & 12 & Sến mủ & 2 & 17 & 20 & 75,80 & 0,61 \\
\hline & 13 & Sp7 & 5 & 35 & 24,6 & 300,71 & 6,01 \\
\hline & 14 & Thành ngạnh & 2 & 21 & 22 & 116,79 & 0,93 \\
\hline & 15 & Thẩu tấu & 2 & 23,5 & 27 & 167,17 & 1,34 \\
\hline & 16 & Trám & 1 & 15 & 19 & 58,94 & 0,24 \\
\hline & 17 & Trâm & 8 & 19,1 & 22,5 & 101,58 & 3,25 \\
\hline \multicolumn{6}{|c|}{ Tổng cộng: } & $2.274,91$ & 36,72 \\
\hline \multicolumn{6}{|c|}{ Tổng cộng $\mathrm{TBC}^{2}$ của 4 OTC: } & $1.546,90$ & 28,23 \\
\hline
\end{tabular}

${ }^{1} \mathrm{OTC}$ : ô tiêu chuẩn.

${ }^{2} \mathrm{TBC}$ là giá trị trung bình cộng của 4 OTC.

\subsection{Lượng cacbon lưu trữ trong tầng cây bụi thảm tươi, vật rơi rụng}

Kết quả nghiên cứu tại 5 ô thứ cấp, sinh khối tươi và sinh khối khô của cây bụi thảm tươi và VRR được tổng hợp tại Bảng 4 .

Kết quả Bảng 4 cho thấy, sinh khối tươi cây bụi thảm tươi dưới tán rừng khộp dao động từ 4,67 $5,61 \mathrm{~kg} / 25 \mathrm{~m}^{2}$ (1,87 - 2,24 tấn/ha). Sinh khối tươi của cây bụi thảm tươi được tính trung bình cho toàn bộ khu vực nghiên cứu là 2,01 tấn/ha. Sinh khối khô của từng bộ phận cây bụi và thảm tươi ở các vị trí khác nhau, dao động từ 2,21 - 3,41 $\mathrm{kg} / 25 \mathrm{~m}^{2}$ (0,88 - 1,37 tấn/ha). Trung bình sinh khối khô của cây bụi thảm tươi là 1,07 tấn/ha. Vật rơi rụng bao gồm thân, cành, lá, hoa, quả rơi rụng và thảm mục. Trong $4 \mathrm{OTC}$ sơ cấp thì sinh khối tươi của VRR dao động từ $0,74-0,93$ $\mathrm{kg} / 25 \mathrm{~m}^{2}(0,30$ - 0,37 tấn/ha), trung bình sinh khối tươi VRR đạt 0,34 tấn/ha. Sinh khối khô của VRR trung bình là 0,19 tấn/ha. Như vậy, kết quả tính sinh khối khô của tầng cây bụi thảm tươi và VRR cho thấy sinh khối khô tập trung trong tầng cây bụi thảm tươi $(1,07$ tấn/ha) nhiều hơn trong VRR (0,19 tấn/ha) (Bảng 5).

\subsection{Lượng cacbon lưu trữ trong toàn lâm phần rừng khộp huyện Ia $\mathbf{P a}$}

Lượng sinh khối khô cây bụi thảm tươi và VRR trên mặt đất, $\mathrm{DW}_{\text {above }}$ là 1,26 tấn/ha. Lượng cacbon tích lũy trong sinh khối cây bụi thảm tươi $\mathrm{W}_{\text {cacbon1 }}=0,5$ tấn $\mathrm{C} /$ ha. Lượng cacbon tích lũy trong sinh khối VRR, $\mathrm{W}_{\text {cacbon }}=0,07$ tấn $\mathrm{C} /$ ha. Lượng cacbon tích lũy trong sinh khối cây bụi thảm tươi và $\mathrm{VRR}, \mathrm{W}_{\text {cacbon }}=0,57$ tấn $\mathrm{C} /$ ha. Lượng cacbon tích lũy trong toàn lâm phần rừng khộp được tính bằng tổng lượng cacbon tích lũy trong tầng cây gỗ, cây bụi thảm tươi và $\mathrm{VRR}, \mathrm{W}$ $=\mathrm{W}_{\text {cacbon }}+\mathrm{W}_{\text {tầng cây gỗ }}=28,8$ tấn $\mathrm{C} /$ ha. Như vậy, lượng $\mathrm{CO}_{2}$ hấp thụ chuyển đổi từ cacbon tích lũy, $\mathrm{M}_{\mathrm{CO}_{2}}$ là 105,6 tấn/ha.

Ước lượng giá trị kinh tế trên cơ sở hấp thụ $\mathrm{CO}_{2}$ : Giá hấp thụ cacbon rừng của đề tài được tính bằng phương pháp giá thị trường. Dựa trên diễn biến giá bán CER trên thị trường, nghiên cứu lựa chọn giá mua bán tín chỉ cacbon trên thị trường (World Bank, 2017). Theo đó, trên thị trường thế giới thì có tới $75 \%$ tổng số nước được thống kê sử dụng mức giá $<10 \mathrm{USD} /$ tấn $\mathrm{CO}_{2}$. Trong đó, số nước sử dụng mức giá 5 USD/tấn 
Bảng 4. SKT và SKK của từng bộ phận cây bụi thảm tươi và VRR của 5 OTC thứ cấp ${ }^{1}$

\begin{tabular}{|c|c|c|c|c|c|c|c|c|c|}
\hline OTC & $\begin{array}{l}\text { Sinh } \\
\text { khối }\end{array}$ & $\begin{array}{c}\text { Bộ } \\
\text { phận }\end{array}$ & $\hat{\mathrm{O}} 1$ & $\widehat{\mathrm{O}} 2$ & Ô 3 & Ô 4 & $\widehat{\mathrm{O}} 5$ & $\begin{array}{c}\text { TBC } \\
\text { (kg/ô thứ cấp) }\end{array}$ & $\begin{array}{c}\text { TBC } \\
\text { (tấn/ha) }\end{array}$ \\
\hline \multirow{10}{*}{1} & \multirow{5}{*}{ SKT } & Thân & 1,90 & 2,50 & 2,20 & 2,00 & 2,10 & 2,14 & 0,86 \\
\hline & & Lá & 1,10 & 1,25 & 1,30 & 1,15 & 1,20 & 1,20 & 0,48 \\
\hline & & Cành & 1,50 & 0,95 & 1,10 & 1,65 & 1,45 & 1,33 & 0,53 \\
\hline & & \multicolumn{6}{|c|}{ Cây bụi thảm tươi } & 4,67 & 1,87 \\
\hline & & VRR & 1,20 & 0,98 & 0,75 & 0,80 & 0,68 & 0,88 & 0,35 \\
\hline & \multirow{5}{*}{ SKK } & Thân & 1,10 & 1,55 & 0,97 & 1,20 & 1,13 & 1,19 & 0,48 \\
\hline & & Lá & 0,33 & 0,50 & 0,44 & 0,51 & 0,46 & 0,45 & 0,18 \\
\hline & & Cành & 0,57 & 0,48 & 0,59 & 0,69 & 0,52 & 0,57 & 0,23 \\
\hline & & & & bụi t & ảm t & & & 2,21 & 0,88 \\
\hline & & VRR & 0,94 & 0,82 & 0,27 & 0,43 & 0,30 & 0,55 & 0,22 \\
\hline \multirow{10}{*}{2} & \multirow{5}{*}{ SKT } & Thân & 2,5 & 2,2 & 2,5 & 2,1 & 2,7 & 2,40 & 0,96 \\
\hline & & Lá & 1,15 & 1,35 & 1,35 & 1,05 & 1,45 & 1,27 & 0,51 \\
\hline & & Cành & 1,6 & 1,1 & 1,2 & 1,18 & 1,55 & 1,33 & 0,53 \\
\hline & & \multicolumn{6}{|c|}{ Cây bụi thảm tươi } & 5,00 & 2,00 \\
\hline & & VRR & 0,7 & 0,85 & 0,82 & 0,6 & 0,75 & 0,74 & 0,30 \\
\hline & \multirow{5}{*}{ SKK } & Thân & 1 & 1,14 & 0,9 & 0,92 & 1,08 & 1,01 & 0,40 \\
\hline & & Lá & 0,71 & 0,78 & 0,70 & 0,61 & 0,81 & 0,72 & 0,29 \\
\hline & & Cành & 1,18 & 0,59 & 0,65 & 0,61 & 1,12 & 0,83 & 0,33 \\
\hline & & & & bụi t & ảm t & & & 2,56 & 1,02 \\
\hline & & VRR & 0,46 & 0,65 & 0,66 & 0,42 & 0,45 & 0,53 & 0,21 \\
\hline \multirow{10}{*}{3} & \multirow{5}{*}{ SKT } & Thân & 3,10 & 2,55 & 2,80 & 3,05 & 2,50 & 2,80 & 1,12 \\
\hline & & Lá & 1,25 & 1,40 & 1,35 & 1,55 & 1,22 & 1,35 & 0,54 \\
\hline & & Cành & 1,40 & 1,68 & 1,50 & 1,45 & 1,25 & 1,46 & 0,58 \\
\hline & & \multicolumn{6}{|c|}{ Cây bưi thảm tươi } & 5,61 & 2,24 \\
\hline & & VRR & 0,95 & 1,12 & 0,75 & 0,90 & 0,93 & 0,93 & 0,37 \\
\hline & \multirow{5}{*}{ SKK } & Thân & 2,23 & 1,99 & 1,57 & 2,32 & 1,70 & 1,96 & 0,78 \\
\hline & & Lá & 0,48 & 0,70 & 0,57 & 0,87 & 0,59 & 0,64 & 0,26 \\
\hline & & Cành & 0,67 & 1,04 & 1,02 & 0,75 & 0,58 & 0,81 & 0,33 \\
\hline & & & & bụi t & ảm t & & & 3,41 & 1,37 \\
\hline & & VRR & 0,55 & 0.52 & 0,35 & 0,61 & 0,52 & 0,51 & 0,20 \\
\hline \multirow{10}{*}{4} & \multirow{5}{*}{ SKT } & Thân & 2,10 & 1,65 & 2,54 & 2,90 & 2,60 & 2,36 & 0,94 \\
\hline & & Lá & 1,10 & 0,95 & 1,15 & 0,98 & 0,80 & 1,00 & 0,40 \\
\hline & & Cành & 1,60 & 1,78 & 1,35 & 1,55 & 1,20 & 1,50 & 0,60 \\
\hline & & \multicolumn{6}{|c|}{ Cây bụi thảm tươi } & 4,85 & 1,94 \\
\hline & & VRR & 0,90 & 0,60 & 0,75 & 0,95 & 0,80 & 0,80 & 0,32 \\
\hline & \multirow{5}{*}{ SKK } & Thân & 1,05 & 0,96 & 1,27 & 1,97 & 1,61 & 1,37 & 0,55 \\
\hline & & Lá & 0,33 & 0,40 & 0,44 & 0,49 & 0,27 & 0,39 & 0,15 \\
\hline & & Cành & 0,64 & 1,03 & 0,84 & 0,74 & 0,62 & 0,78 & 0,31 \\
\hline & & \multicolumn{6}{|c|}{ Cây bụi thảm tươi } & 2,53 & 1,01 \\
\hline & & VRR & 0,54 & 0,38 & 0,21 & 0,40 & 0,27 & 0,36 & 0,14 \\
\hline
\end{tabular}

${ }^{1}$ SKT: sinh khối tươi; SKK: sinh khối khô; VRR: vật rơi rụng; OTC: ô tiêu chuẩn. 
Bảng 5. Trung bình $S K T$ và $S K K$ của từng bộ phận cây bụi thảm tươi và VRR của $4 \mathrm{OTCSC}^{1}$

\begin{tabular}{lcc}
\hline Sinh khối & TBC $\left(\mathrm{kg} / 25 \mathrm{~m}^{2}\right)$ & TBC (tấn $/$ ha) \\
\hline SKT $_{\text {cây bụi thảm tươi }}$ & 5,03 & 2,01 \\
SKK $_{\text {cây bụi thảm tươi }}$ & 2,68 & 1,07 \\
SKT VRR $_{\text {SKK }}$ & 0,84 & 0,34 \\
V $_{\text {VRR }}$ & 0,54 & 0,19 \\
\hline
\end{tabular}

${ }^{1}$ SKT: sinh khối tươi; SKK: sinh khối khô; VRR: vật rơi rụng; OTCSC: Ô tiêu chuẩn sơ cấp; TBC: Trung bình cộng.

Bảng 6. Giá trị kinh tế ước tính từ việc hấp thụ $\mathrm{CO}_{2}$ của rừng tại huyện Ia $\mathrm{Pa}$

\begin{tabular}{cccc}
\hline STT & Loại đất rừng & Diện tích (ha) & Thành tiền (VNĐ) \\
\hline \multicolumn{2}{c}{ Tổng diện tích đất lâm nghiệp } & $53.391,75$ & 657.141 .013 .917 \\
1 & Rừng tự nhiên & $46.869,37$ & 576.482 .002 .351 \\
\hline
\end{tabular}

$\mathrm{CO}_{2}$ chiếm tỉ lệ cao nhất. Vì vậy, nghiên cứu chọn mức giá $5 \mathrm{USD} /$ tấn $\mathrm{CO}_{2}$ để tính. Như vậy, ước tính giá trị kinh tế hấp thụ $\mathrm{CO}_{2}$ của huyện Ia $\mathrm{Pa}$ được trình bày trong Bảng 6 .

Từ kết quả ước lượng trên cho thấy lượng $\mathrm{CO}_{2}$ tích lũy trong 1 ha rừng khộp khoảng 105,60 tấn (gồm lượng $\mathrm{CO}_{2}$ hấp thụ từ cây thân gỗ, cây bụi thảm tươi và VRR trên mặt đất), tương ứng với giá trị tiền bán ra thị trường là $528 \mathrm{USD} / \mathrm{ha}$ tương đương 12.299.760 VNĐ/ha. Huyện Ia $\mathrm{Pa}$ với 46.869,37 ha rừng tự nhiên tương đương với giá trị kinh tế hấp thụ $\mathrm{CO}_{2}$ khoảng 576 tỷ VNĐ. Đây là một giá trị không hề nhỏ đối với người quản lý rừng, đặc biệt là các cộng đồng dân tộc thiểu số vùng cao đang quản lý các khu rừng cộng đồng, đây thực sự là nguồn thu lợi nhuận rất đáng quan tâm.

\section{Kết Luận}

Huyện Ia $\mathrm{Pa}$ với $46.869,37$ ha rừng tự nhiên tương đương với giá trị kinh tế hấp thụ $\mathrm{CO}_{2}$ khoảng 576 tỷ VNĐ. Đây là một trong những giá trị môi trường rất lớn đối với rừng khộp tại đây. Tuy nhiên, năng lượng hấp năng hấp thụ cacbon có thể thay đổi theo mùa, đặc biệt là những mùa tiêu điểm của cháy rừng thì lượng cacbon tích lũy trong sinh khối rất ít. Vì vậy, cần có các nghiên cứu về khả năng hấp thụ cacbon theo mùa của rừng khộp tại $\mathrm{Ia} \mathrm{Pa}$.

\section{Tài Liệu Tham Khảo (References)}

IPCC (The Intergovernmental Panel on Climate). (2006). IPCC Guidelines for National Greenhouse Gas Inventories. Hayama, Japan: IGES.

Luong, T. V., Vu, P. T., \& Luong, H. X. (2011). Research on the effectivity of Carbon sequestration values of big timber plantations in Vietnam. Vietnam Journal of Forest Science 4, 1-7.

Vu, Q. D., \& Vo, H. D. (2014). Study on carbon storage ability of dry dipterocarp forest in Central Highlands in Vietnam. Vietnam Journal of Forest Science 2, 3308-3317. World bank. (2017). State and Trends of Carbon Pricing 201\%. Washington DC, USA: World bank.

IPDFPD (Ia Pa District Forest Protection Department). (2018). Report on forest protection and management in 9 months and directions, tasks in the last 3 months of 2018. Gia Lai, Vietnam: IPDFPD Office. 